\title{
A economia brasileira e as mudanças estruturais pós anos 1980: novo paradigma, novas instituições ou novo desenvolvimentismo?
}

Octavio Augusto Camargo Conceição*

Resumo: Este texto será dividido em 5 seções. Nas primeiras duas seções será feita uma breve discussão teórica acerca do papel da mudança tecnológica e institucional nas abordagens neo-schumpeterianas e institucionalistas, respectivamente. O objetivo será explicitar o nexo de convergência entre ambas as abordagens, demonstrando que constituem um amplo e fértil campo de pesquisa sobre crescimento econômico. Na terceira seção será apresentada uma breve avaliação da evolução da economia brasileira ao longo das últimas três décadas, buscando identificar as principais mudanças estruturais, quais sejam, mudanças tecnológicas e institucionais, que ocorreram ao longo do período. Na quarta seção será feita uma breve avaliação da relação entre o conceito de "novo desenvolvimentismo" com a abordagem teórica proposta. Por fim, estabelecer-se-ão algumas considerações.

Palavras-chave: Economia Brasileira; Institucionalismo; Evolucionismo

Classificação JEL: B25, B52, E60

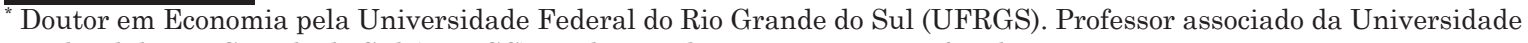
Federal do Rio Grande do Sul (UFRGS). Endereço eletrônico: octavio@ufrgs.br 


\section{Introdução}

Poucos períodos da história recente do Brasil foram palco de tão profundas e complexas transformações como as que transcorreram ao longo das últimas três décadas. Atravessou-se, desde o final dos anos de 1970, um período de uma profunda crise econômica, associado a um processo inflacionário sem precedente na história do País, que exigiram uma drástica correção de rumo. Tal correção, apesar de lenta e, às vezes, aparentemente, sem norte, veio ocorrendo desde então, tornando-se perceptível apenas no início dos anos de 1990. Ali, já se podia observar que a economia nacional exigia reformas estruturais profundas para sua sobrevivência.

Ou seja, os anos de 1980 explicitaram a impossibilidade de a economia funcionar da forma em que estava estruturada. Para poder sustentar alguma trajetória de crescimento de mais longo prazo, faziam-se necessárias reformas (estruturais) que rompessem, simultaneamente, com a "lógica" da memória inflacionária, com um padrão de ação governamental que não produzia mais resultados, senão déficits recorrentes, com um regime de competitividade (que, mais tarde, o cepalino Fernando Fajnzylber denominou de "competitividade espúria") assentado na desvalorização cambial, com um padrão produtivo herdado do modelo tecnologicamente passivo do processo de substituição de importações (PSI) e com uma organização do trabalho que propiciasse ganhos de produtividade e qualificação da mão de obra.

Some-se a isso que esse quadro de mudanças ocorreu em meio ao triunfo do denominado "neoliberalismo", que defendia maior flexibilização do mercado de trabalho, políticas restritivas à demanda agregada e um padrão de ação estatal avesso a qualquer identificação com o Keynesianismo. Esse elenco de medidas, que John Williamson chamou de "Consenso de Washington", articulou a grande orquestração macroeconômica dos anos de 1980 e 1990, que regeu a política econômica das nações ocidentais. $\mathrm{O}$ alinhamento a essas reformas foi responsável, em grande parte, pelas diferentes performances nacionais ao longo dos anos de 1990.

A série de mudanças levadas a efeito no Brasil nesse período não fugiram desse espectro. Tal processo se desencadeou de maneira contínua, irreversível e não sem sobressaltos. Manifestou-se, também, através da geração de um enorme ônus para a população, para as empresas e para o próprio Estado, cujo processo de "ajuste", revelado através de sucessivas mudanças estruturais, transformou, irreversivelmente, a face da economia nacional.

Este texto será dividido em 5 seções. Além desta introdução, na segunda e na terceira seção será feita uma breve discussão teórica acerca do papel da mudança tecnológica e institucional nas abordagens neo-schumpeterianas e institucionalistas, respectivamente. O objetivo será explicitar o nexo de convergência entre ambas as abordagens, demonstrando que constituem um amplo e fértil campo de pesquisa sobre crescimento econômico. Na quarta seção será apresentada uma breve avaliação da evolução da economia brasileira ao longo das últimas três décadas, buscando identificar as principais mudanças 
estruturais, quais sejam, mudanças tecnológicas e institucionais, que ocorreram ao longo do período. E na quinta seção será feita uma breve avaliação da relação entre o conceito de "novo desenvolvimentismo" com a abordagem teórica proposta. Por fim, estabelecer-se-ão algumas considerações.

\section{Breves notas sobre evolução econômica e o papel da mudança tecnológica}

A economia evolucionária trata de sistemas complexos que interagem em um mundo de diversidade, onde as inovações exercem papel central. Nesse sentido, o processo de crescimento e de desenvolvimento econômico está inserido em um processo de mudança estrutural, que permite que as mudanças tecnológicas e institucionais se alimentem reciprocamente (embora com timings diferentes), operando assim as mudanças sociais.

O conceito de mudança e o processo de mudança estrutural será, aqui neste texto, entendido como sendo, simultaneamente, de natureza tanto tecnológica, quanto institucional. Sua compreensão está igualmente associada à descrição, dentro das diferentes realidades regionais, dos elementos que constituem o processo de crescimento econômico, que lhes são específicos. Para tal descrição, porém, é necessário que se realize, no plano analítico e teórico, a inclusão das instituições que operam dentro do referido ambiente evolutivo.

A nosso ver, compreender crescimento e instituições "fora" da noção evolutiva, além de empobrecer a análise, esvazia-a de conteúdo histórico, como, aliás, o fazem as abordagens convencionais ou standard (Nelson, 2002). Instituições, crescimento econômico e evolução são noções indissociáveis. Por essa razão, julga-se pertinente retomar a definição do que vem a ser, em termos atuais, o conceito de evolução.

A compreensão da natureza da mudança econômica tem sido um dos mais férteis campos teóricos em economia nas últimas três décadas. Várias correntes articularam-se e desenvolveram-se buscando responder o que a determina. Contrasta com essa busca, a ausência de tratamento teórico ao referido processo pelo mainstream ortodoxo, que deliberadamente o negligenciou. Um dos pilares fundamentais no avanço da compreensão do processo de mudança econômica foi o trabalho seminal de Richard Nelson e Sidney Winter, publicado em 1982, intitulado An Evolutionary Theory of Economic Change. Nesse estudo, desenvolveu-se a base do que seria uma interpretação alternativa ao processo de crescimento econômico, que exigiria a construção de um novo marco de análise. Tal tarefa foi levada a efeito pela contribuição então designada de neoschumpeteriana, que, com vários trabalhos em sequência, perseguindo uma agenda de pesquisa comum, avançou substancialmente na compreensão dos fenômenos de crescimento e desenvolvimento tecnológico, mudança estrutural, paradigmas tecnológicos ou tecno-econômicos, trajetórias tecnológicas e sistemas nacionais de inovação. Além de Nelson e Winter, somaram-se a essa escola Giovanni Dosi, Christopher Freeman, Lundvall, Carlota Perez, Luc Soete, 
Brian Arthur e muitos outros. Para eles, o que dava sustentação ao processo de crescimento e de desenvolvimento econômico era a forma como se organizavam e se disseminavam as novas tecnologias, o ambiente à inovatividade, o padrão de competitividade e o ambiente institucional mais ou menos propício às mesmas. $\mathrm{O}$ grau de êxito ou fracasso dos países em direção a esse desiderato era resultante da forma como nacional ou regionalmente operou esse padrão.

$\mathrm{O}$ ambiente econômico, ao ser instigado pela necessidade de mudanças, adapta-se ao novo paradigma, construindo uma rede institucional capaz de sustentar o espectro de transformações dele decorrentes. Tal processo se dissemina tanto no âmbito da firma, quanto no processo de trabalho, na gestão dos novos métodos produtivos, estabelecendo capacitações (Dosi, 1988a) e aprendizagem. Estas absorvem os novos padrões de competitividade, decorrentes da mudança estrutural originária do paradigma dominante, e os disseminam. Por essa razão, na ótica neo-schumpeteriana, tecnologia é definida como um processo de busca de novos produtos e processos, que se difundem por todo o sistema. Aliás, é por essa razão que Nelson (2008) vem propondo o conceito de "tecnologia social", que articula as rotinas das firmas com as instituições e com a tecnologia (Conceição, 2009).

Essa interação produz, ao longo do tempo, mudança nos padrões de comportamento, nos hábitos, nas normas e nas regras do jogo, estabelecendo um novo marco institucional. Hodgson (2007) designa essa noção como de reconstitutive downward causation, que estabelece o nexo entre indivíduos, seus hábitos e crenças e as instituições, que determinam e são influenciadas pelos mesmos.

O referido processo, ao contrário da visão dominante no mainstream, tem pouco a ver com o desenho de uma trajetória de crescimento convergente a um ponto de "equilíbrio ótimo", compatível com a noção de steady state, embora possa advir alguma estabilidade provisória dessas transformações. Mudanças, instabilidade e incerteza predominam ante o quadro hipotético de convergência à estabilidade e ao equilíbrio de longo prazo. Douglass North, importante referência da Nova Economia Institucional (NEI), tem afirmado em seus trabalhos mais recentes que as diferentes performances econômicas dos países (e consequentemente das regiões) são resultados das mudanças institucionais ali operadas. Tal proposição nos credencia a enfatizar a importância teórica em se identificar como as referidas mudanças institucionais se processaram na economia brasileira nas últimas três décadas, e em particular no último decênio.

Neste sentido, e em sintonia com a noção de paradigma tecno-econômico de Perez (2007), é importante mencionar que, ao longo dos últimos 30 anos, atravessamos uma fase da economia mundial dominada pelo "paradigma tecnológico da informação". Esse definiu, para os países periféricos, as possibilidades de abrir (ou fechar) as "janelas de oportunidade", conforme a forma de enfrentamento dos desafios da tecnologia e da competitividade. A escolha de uma ou outra forma é quem determinará as condições de avanço tecnológico, social, econômico e institucional.

Sob a ótica de Perez (2007), o período atual, após o colapso da grande 
bolha da tecnologia, estaria no ponto médio da grande onda corrente, que ocorre quando as tensões estruturais realçam as instabilidades e as tendências recessivas, as quais, por sua vez, exigem uma outra recomposição institucional. Assim, o momento presente é, pelas razões expostas, o mais apropriado possível para levar adiante corajosas propostas para um profundo redesenho da regulação global e das instituições.

Portanto é sob essa forma que ocorre a mudança tecnológica, que arrasta consigo - não de forma automática, mas "induzida" pelo processo de busca - as mudanças institucionais que proliferam em conjunto e de forma articulada. São estas as circunstâncias que levam ao progresso econômico.

\section{Instituições e mudança institucional}

Dentro desse contexto, pode-se definir instituição como conjunto de normas, regras, hábitos e sua evolução (Hodgson, 2000; North, 1990; e Nelson, 1995). Daí infere-se que a instituição passa a viabilizar, em função das raízes históricas e estruturais que lhes são específicas, distintas trajetórias de crescimento econômico. Por esta razão instituição, crescimento econômico e paradigma tecno-econômico são conceitos interligados.

Essas ponderações recolocam a ênfase em questões que formalmente nunca deveriam ter sido omitidas, tais como a de que crescimento econômico constitui-se em: (a) um processo de rupturas e reconstruções; (b) as características da transição de um velho para um novo processo de crescimento são elementos decisivos para a análise; (c) as mudanças estruturais de natureza tanto tecnológica, quanto institucional, são fundamentais; e (d) apesar de o mesmo sempre se apresentar quantitativamente como um incremento na relação produto-capital - ou aumento da acumulação de capital per capita superior ao crescimento populacional, ou ainda crescimento da produtividade do capital em relação ao aumento da população -, ele reveste-se de características bastante distintas de região para região, às vezes sequer comparáveis. E é exatamente desses aspectos que se ocupa a tradição institucionalista: a história importa, as formas de crescimento capitalista são diferenciadas e múltiplas, o processo de crescimento é contínuo e tem raízes históricas profundas (North, 2005, Hodgson, 2002).

Sob essa perspectiva conceitual, o fenômeno do crescimento econômico deve ser entendido como manifestação de mudanças institucionais. Portanto, o vínculo entre crescimento e instituições deve ser realizado pelo conceito de mudança, que pressupõe inovações (Matthews, 1986, p. 908). Para John Zysman (1994), as trajetórias de crescimento são criadas historicamente, a partir do desenvolvimento de trajetórias nacionais institucionalmente inventadas ou enraizadas (Historically Rooted Trajectories of Growth). Ou seja, as instituições importam, porque determinam diferentes trajetórias de crescimento econômico nos diversos ambientes nacionais. Há várias formas de se organizar as economias de mercado, os mercados são diferentes e há vários tipos de capitalismo. Em Douglass North (1990), o fundamental no 
campo do desenvolvimento econômico é buscar a formulação de uma ainda inexistente "teoria da dinâmica econômica". E esta reside fundamentalmente na compreensão e sistematização do processo de mudança. Em sendo assim, as trajetórias das mudanças institucionais são elementos essenciais na definição das diferentes formas de crescimento econômico, o que revela notável semelhança com o pensamento evolucionário. Para North, a mudança econômica de longo prazo é uma "conseqüência cumulativa" de inúmeras decisões de curto prazo tomadas por políticos e empresários, que, direta ou indiretamente (via efeitos externos), determinam a performance econômica. Entretanto, o grau, através do qual os resultados são consistentes com as intenções, refletirá o grau através do qual os modelos dos empresários são efetivamente "verdadeiros". Isto porque os modelos refletem idéias, ideologias e crenças que são, na melhor das hipóteses, apenas parcialmente refinadas e melhoradas por feedback de informações sobre as conseqüências atuais das políticas tornadas legitimamente legais. Em outros termos, as conseqüências de políticas específicas não são apenas incertas, mas imprevisíveis.

\section{Três décadas de evolução da economia brasileira}

A instrumentalização teórica de noções, como as de mudança tecnológica e institucional, integra uma rica agenda de pesquisa, que, a nosso ver, vem repercutindo de maneira ainda tímida sobre o ambiente econômico nacional e regional. Poucos estudos ocupam-se dessa questão. A forma como operaram, no espaço regional, as referidas transformações econômicas, são fundamentais para que se entenda o atual desenho da economia gaúcha, sua relação com a dinâmica nacional, sua forma de inserção com o exterior e os desafios futuros daí decorrentes. Esse artigo supõe que a literatura institucionalista e evolucionária vem dando importantes passos nesse sentido. A nosso ver, seria pouco frutífero, senão impossível, tentar compreender o amplo elenco de mudanças que ocorreram na economia gaúcha e brasileira, no período em questão, sem a incorporação do instrumental teórico evolucionário e institucionalista, que discutiremos brevemente na próxima seção.

A crise da década de 1980 e as expectativas de hiperinflação estabeleceram estratégias de sobrevivência denominadas de "defensivas" postura impedia avanços na ótica produtiva, colocando o setor passivamente no aguardo da definição de um ambiente mais estável para o crescimento, que se demonstrava cada vez mais difícil, distante e menos visível.

O que importa reter aqui não é um exame pormenorizado das mudanças no âmbito da estrutura produtiva nacional, que decorreu da amplitude das mudanças que se esboçaram no plano microeconômico da firma e se disseminaram no âmbito meso-econômico, conferindo certa especificidade na forma como o

1 Saliente-se que esse tipo de "estratégia defensiva" foi típica na economia brasileira de forma mais visível nos anos 90, quando as empresas, para sobreviver ante a abrupta abertura externa, adotaram estratégias de enxugamento de seus quadros funcionais, downsizing, etc., que muito mais do que revelar um quadro de modernização dos ganhos de produtividade do trabalho frente às novas tecnologias, geraram forte precarização do mercado de trabalho (Castro, 1996, 1997). 
paradigma tecno-econômico se desenvolveu no interior da estrutura produtiva local. Explicando melhor: o esgotamento do paradigma de produção em massa, que respondeu por enormes avanços industriais na economia brasileira nos anos 50 a 70, deu sinais de esgotamento nos anos 80. Perda de competitividade, desestímulo a inovações tecnológicas, passividade tecnológica e ajustes à estrutura de custo dada, sem busca de novas tecnologias e, portanto, ganhos de produtividade, inibiram as frentes de expansão produtiva, culminando em estratégias defensivas e ganhos eventuais em lucratividade, via câmbio ou via inflação.

Esse padrão criou um ambiente produtivo pouco ousado e pouco eficiente, explicitando a falência do padrão industrial originado pelo PSI. As mudanças se faziam necessárias, mas a base produtiva regional, em sua grande maioria, não percebia para onde direcioná-las. Essa indefinição culminou na designação de "década perdida" ou ausência de novas janelas de oportunidade.

O que se sucedeu a partir daí foi o aparecimento de uma série de transformações cumulativas, que poderiam originar uma "nova" economia brasileira, cujos contornos ainda não estão precisos, mas vem respondendo por grande parte de sua performance. Pôs-se em marcha o processo de destruiçãocriadora, encorajado pelo surgimento de mutações internas. Sob essa ótica, a abertura externa, no início dos anos 90, surgiu não como fruto de uma decisão "autônoma" nacional, face à precária inserção nacional no padrão de competitividade internacional, mas, isso sim, como uma necessidade estrutural às novas condições de crescimento da economia brasileira, ainda longe de serem visualizadas no espaço produtivo nacional. Não se sabia o que adviria daí, mas era certo que a economia brasileira deveria ter um desenho estruturalmente diferente do que persistira até o início dos anos 90 .

Dois outros fatores, de natureza interna - foram eles a desindexação com o Plano Real e a convivência com a paridade cambial fixa - terminaram por quebrar (de forma supostamente definitiva) os hábitos, as regras e os padrões de conduta herdados do PSI, que se enraizaram na forma de "produzir" dentro da economia brasileira. Trata-se do padrão de comportamento associado à inflação, onde o produtor habitou-se a incorporar, no seu preço final, as expectativas inflacionárias, delegando aos ganhos de produtividade e de eficiência produtiva um padrão marginal e exógeno à linha de produção nacional. Esse comportamento precário e refratário frente aos desafios da competitividade, explica, em parte, a fragilidade tecnológica do padrão produtivo nacional herdado do referido processo. A mudança de regras para a sobrevivência aos novos padrões (mais modernos) de competitividade não se fez sem grandes transtornos, falências, quebradeiras. Autores como Conceição Tavares, parodiando Schumpeter, mas em sentido negativo, preferiram designar esse período como o de "destruiçãonão-criadora" (Tavares, 1999). O estudo do ECIB buscou, com grande fôlego, identificar de maneira precisa os desafios dessa época (Coutinho \& Ferraz, 1994). 


\subsection{Os anos de 1980: inflação e corrosão da herança substitutiva}

A década perdida dos anos de 1980 revelou perda de dinamismo da economia brasileira, que, depois do período de grande crescimento, caracterizado pelo "milagre econômico" de 1967-73, desacelerou, no pós 74, sua taxa de crescimento até chegar a variações negativas do PIB já em 1981. Até então, não se tinha conhecimento, dentro da estrutura produtiva brasileira, de crescimento negativo, pelo menos desde a construção da industrialização via PSI. Vários artigos e textos, que se tornaram clássicos, analisaram essa questão e não caberia recapitulá-los aqui. O fundamental é destacar que importantes elementos de natureza estrutural bloquearam, impediram e obstaculizaram a possibilidade de a economia nacional - e, consequentemente, as economias regionais - continuar "crescendo" e "funcionando" nos moldes vigentes. Esgotara-se a capacidade de acumulação de capital via substituição de importações.

A incompreensão das mudanças em curso, a partir dos anos de 1980, reeditou, no plano das "convenções", das normas de comportamento doméstico (leia-se instituições), práticas produtivas totalmente incompatíveis com a "modernidade" de então. Como estratégia de sobrevivência à dramática "crise dos 80", o mecanismo de reindexação dos ativos, como forma de proteção ao setor financeiro - que, diga-se de passagem, fora criado em 1966 pela reforma CamposBulhões, que instituiu o expediente da correção monetária -, disseminou-se por toda a economia. Tal mecanismo não se constituiu apenas em proteção dos ativos financeiros contra a inflação, mas contagiou todos os contratos da economia, desde contratos financeiros de crédito, contratos de compra e venda, contratos de trabalho, tributação e, mais importante, passou a fazer parte da decisão de produzir dos agentes. A decisão empresarial de qualquer empreendimento embutia a expectativa de inflação no período, que passou a superar qualquer risco oriundo da própria atividade capitalista. Ingressava-se no pior dos mundos: a produção sem risco, caucionada pela inflação e avalizada pela dívida pública interna, que também passou a financiar-se com o referido processo.

A perversidade dessa política é por demais conhecida como elemento altamente concentrador da renda. Além disso, a instituição da convenção do "crescimento-com-inflação" (Castro, 1997) minava qualquer possibilidade de modernização da economia brasileira, já que anulava quaisquer perspectivas de enfrentamento de novas estratégias frente a crise. O "curto prazismo" e as preocupações com a inflação, e com o consequente financiamento da mesma, via aplicações financeiras, alimentaram não só um processo de resistência à desinflação, como fomentaram uma voraz financeirização, que obstaculizava a queda da inflação. O cálculo econômico das empresas, das famílias e do governo sancionava a vigência e a suposta necessidade do referido mecanismo. As estratégias empresariais de modernização eram assim bloqueadas e as aplicações de curtíssimo prazo passaram a reger a economia brasileira.

As tentativas de reverter esse processo, que só alimentava a concentração da renda, resultaram em grande fracasso. Os planos heterodoxos de combate à inflação não conseguiam quebrar a inércia desses mecanismos. O Plano Cruzado, 
o Plano Bresser, o Plano Verão - e posteriormente, os Planos Collor I e II nos anos de 1990 - não conseguiram romper com a memória inflacionária, que nada mais era senão a institucionalização da inflação dentro da economia brasileira. Fazia-se necessária uma "nova economia", que começou a ser construída apenas em meados da década seguinte.

Genericamente, pode-se concluir que a década de 1980 foi perdida pelo fato de não se ter conseguido construir qualquer possibilidade de recuperação econômica. Isto se deu por três razões: pela precária capacidade de inserção no paradigma tecnológico em construção; pela cegueira generalizada em relação a perspectivas de longo prazo, que o processo de aceleração inflacionária trouxe; e pela inexistência de um padrão de ação estatal capaz de vislumbrar alternativas de política econômica capazes de reverter esse caótico quadro.

Mais ainda, nos anos de 1980, explicitou-se que não bastava à política econômica governamental "querer" acabar com a inflação, era necessário que a população acreditasse em tais intenções. Em outros termos, era necessário combinar intenção e consistência macroeconômica com credibilidade no âmbito microeconômico dos agentes e tomadores de decisão. Essa foi uma terceira lição herdada dos tempos da crise: não basta os governantes e sua política econômica quererem ou terem intenção de extirpar elementos nocivos à economia, enraizados institucionalmente no País. Era e continua sendo necessário estabelecer um horizonte de credibilidade capaz de torná-los aceitáveis e passíveis de incorporação no âmbito microeconômico das decisões descentralizadas dos agentes econômicos. Leia-se, é fundamental uma mudança de hábitos (à la Veblen) para obter-se tal objetivo. Em outros termos, o fracasso dos Planos Heterodoxos de combate à inflação nos anos de 1980 deveu-se menos a consistência interna dos mesmos (que, como se viu anos mais tarde, também era problemática) do que à falta de um ambiente institucional e microeconômico para sua aceitação.

\subsection{Os anos 1990 e a necessidade de reestruturação}

O ingresso nos anos ocorreu em meio a grandes perspectivas de mudanças. O país acabara de ter eleições diretas para a Presidência da República, a inflação encontrava-se em elevação acelerada e o fracasso dos choques heterodoxos, herdados da era Sarney, exigiam drásticas "correções de rumo" (para se usar expressão da época). Sucedeu-se daí o Plano Collor I e II, em 1990 e 1991, respectivamente, que não só foram incapazes de reverter a inércia inflacionária, como desorganizaram ainda mais a economia do País.

Entretanto, uma medida relevante foi tomada: a abertura comercial. A abrupta exposição às condições de competitividade externa revelou a precariedade da estrutura produtiva nacional em sobreviver em condições adversas. A fragilidade do padrão de competitividade vigente no País explicitouse não só como resultado direto do mecanismo de proteção cambial, oriundo do regime de alta inflação, mas também como resultado de anos de convívio com uma economia fechada (pouco exposta à concorrência externa), fruto do PSI, 
que ora explicitava seu esgotamento. $\mathrm{O}$ ajuste foi dramático e várias empresas faliram. Mas, estruturalmente, tal exposição foi necessária, visto que, anos mais tarde, as empresas sobreviventes sairiam fortalecidas. Estava em marcha o mecanismo de destruição-criadora a que Schumpeter se referia. E a economia gaúcha se valeu desse mecanismo.

Apesar do duro e penoso desafio de reinserção externa - sem uma contrapartida doméstica em termos uma infra-estrutura organizacional, produtiva e tecnológica para enfrentar os padrões de concorrência do "novo" paradigma tecnológico em plena ascensão - tornou-se clara a necessidade de reestruturação produtiva brasileira. E isso foi feito, caracterizando a primeira grande mudança estrutural dos anos de 1990. Vários estudos trataram dessa questão e não será feita uma releitura dos mesmos (Coutinho e Ferraz, 1994; Franco, 1995). Interessa reter aqui que a economia brasileira buscava novos fundamentos para sua evolução, cujo primeiro passo havia sido dado.

O episódio do impeachment de Collor e a posse de Itamar Franco em 1992 evidenciaram a imperiosidade em reverter, e rapidamente, o caótico cenário de instabilidade inflacionária, que carregava consigo a ameaça de hiperinflação e a perda total da governabilidade do País. Começou-se a gestar aí um novo desenho de estabilização econômica: um outro plano, mas sem congelamento de preços, sem choques, sem surpresas, sem bloqueio de liquidez, com regras claras de desindexação e alguma garantia de que a população não seria surpreendida com congelamento de preços, como acontecera em planos anteriores. Além disso, implícito nesse novo plano, estava a preocupação central com o ajuste fiscal e com o papel do governo como gerenciador da política econômica. Tais elementos constituíram a base do Plano Real, implementado em julho de 1994.

Originou-se daí a segunda mutação estrutural nos alicerces da economia brasileira nos anos de 1990, que, simultaneamente, operou duas outras mudanças institucionais de grande profundidade. De um lado, mudou o regime monetário, introduzindo uma nova moeda, com paridade cambial equivalente ao dólar, e, de outro lado, mudou a forma de ação do Estado, que passou a perseguir ajuste fiscal, metas de superávit fiscal, controle monetário e compromisso orçamentário. Desfazia-se o Estado-empresário da substituição de importações e incorporavase novos elementos compatíveis com um maior rigor fiscal.

Como se viu, mudança não significa "melhora", mas evolução, mutação, o que implica afirmar que o novo desenho institucional do Estado passou a compatibilizar-se com o ideário da globalização. Como salientado por Perez, a nova função do Estado, introduzida com o Plano Real, passou a sintonizarse com o denominado "Consenso de Washington", seguindo os princípios, ditos neoliberais, de Estado mínimo, privatizações, superávit fiscal e renúncia a atividades produtivas (ou empresariais). Com o ambiente de estabilização e sem inflação, tais funções passaram a ser exigidas, já que o financiamento do déficit via inflação, como ocorrera na década de 80, não mais seria possível. O papel do Estado redefiniu-se e as metas de superávit fiscal passaram a desempenhar papel proeminente, embora o endividamento financeiro do mesmo continuasse elevado. 
O desenho institucional do País, nesse período, passou a orientarse por uma adesão explícita ao modelo vigente nos países desenvolvidos, orientados pelo que se convencionou designar de "Consenso de Washington". Idéias liberalizantes, controle da ação estatal, flexibilização dos mercados e privatizações passaram a ser atônica da gestão pública, revelando uma total fragmentação do "velho" estado desenvolvimentista, sem apropriar-se de um novo papel, a não ser uma oposição aos princípios até então dominantes.

Tal falta de rumo foi acompanhada por um brutal crescimento da dívida pública, herança do regime inflacionário, sem a constituição de maior rigor fiscal, que tornaram a administração pública extremamente difícil. Tal processo se deu tanto na órbita federal, quanto na estadual. No âmbito federal, a perseguição de uma maior carga fiscal, via contração fiscal, teve dois efeitos. De um lado, os esforços da União para debelar o processo inflacionário (via maior rigor fiscal e monetário) expunham à população a firme intenção de criar um ambiente de estabilização, fomentando expectativas nesse sentido, e, de outro lado, induzia uma mudança de mentalidade, através da tentativa em zerar a memória inflacionária. Entretanto, mesmo com aumento da carga tributária, a ação estatal não conseguia "fazer caixa", gerando uma situação de deterioração financeira, que, apesar das tentativas de governos posteriores, persiste até os dias de hoje.

Todo esse quadro revela que o custo da estabilização, que se consolidava ao longo da década, do ponto de vista da gestão estatal, foi extremamente difícil, implicando perda de controle sobre os gastos, o qual, por sua vez, gerou aumento da dívida pública dos estados, oriunda da escassez de fontes de financiamento em um regime sem inflação. Por conta desse processo reduziu-se sobremaneira a ação estatal, delegando à administração governamental pouca (ou nenhuma) autonomia em relação à decisão de expandir ou estimular a capacidade produtiva, frente a incapacidade de investimento.

O Estado, tanto no âmbito nacional quanto regional, deixou de ser "empresário" para se constituir em gerente, parceiro e gestor. Essa mudança institucional foi fundamental para o desenho da nova forma de ação estatal, que se tornou mais clara na década seguinte.

A persistência do quadro referido acima, pautado pelas dificuldades oriundas das diretrizes da estabilização, trouxe consigo a "convenção" de que sem "arrumar a casa", ou, em linguagem corrente na época, construir "bons fundamentos macroeconômicos", dificilmente poderia ser trilhada qualquer trajetória de crescimento mais consistente. Por essa razão, a economia brasileira e a gaúcha não conseguiam obter saltos expressivos em termos de taxa de crescimento do produto.

A reversão das expectativas inflacionárias, que foi se consolidando com o Plano Real, realizou-se mediante um desenho de política econômica centrado no tripé metas de inflação, superávit fiscal e juros altos. Tal opção, além de não deixar muito espaço para que novas trajetórias de crescimento econômico pudessem ser trilhadas, reforçou o alinhamento da política econômica nacional - e, por derivação, o ambiente regional da economia gaúcha - às regras vigentes no ambiente econômico internacional, orientado pelos princípios do "Consenso de 
Washington”. Contraditoriamente, o cenário econômico externo experimentou, ao longo dos anos de 1990, um surpreendente - mas não sustentável - clima de prosperidade e de crescimento econômico (aparentemente) auto-sustentado, amparado pela forte financeirização e pela expansão dos mercados asiáticos.

A economia brasileira, ao contrário, amargou uma situação de baixas taxas de crescimento doméstico, pesada carga tributária, rígido controle da demanda agregada e forte fluxo financeiro externo, sintonizado com os altos juros praticados internamente. Como resultado, elevou-se a dívida pública interna e os desequilíbrios fiscais, inviabilizando estratégias governamentais mais ousadas, principalmente no sentido de vincular as decisões de investimento às atividades geradoras de inovação em P\&D. Dessa forma, deixou-se de estimular um padrão de organização industrial mais sintonizado com os avanços do novo paradigma tecnológico da informação, inviabilizando um ambiente mais propício a sinergias e janelas de oportunidade nesse sentido.

De fato, o País cresceu pouco, mas as mudanças institucionais foram significativas. Vivia-se o novo, sem o conhecimento prévio do que, de fato, o mesmo se constituiria. E negava-se o velho, com a certeza de que jamais voltaria a predominar. Tal foi o quadro da mutação dos anos de 1990, que deixou um legado fundamental para o primeiro decênio do século XXI. As reformas econômicas operaram de forma agressiva, não obstante os avanços sociais não tenham ocorrido de forma expressiva. Porém, o terreno para que tais avanços se consumassem estava virtualmente construído. Caberia aos futuros governantes abrirem janelas de oportunidade nesse sentido. O palco histórico dos anos de 2000 revelaria ou sepultaria tais possibilidades.

\subsection{Os anos 2000: a década do "reordenamento obediente" versus o novo desenvolvimento}

A economia brasileira ingressa no século XXI instigada por dois momentos, que, literalmente, puseram em xeque os alicerces macroeconômicos, construídos a partir dos primeiros desdobramentos do Plano Real. O primeiro momento ocorreu em janeiro de 1999, quando do início do $2^{\circ}$ mandato de FHC, que explicitou a crise cambial de 1999. Na época, temia-se que a mesma abalaria os alicerces da estabilização nacional. A reação de então, respondida pela adoção da política de maior flexibilização cambial, superando o mecanismo de paridade cambial fixa, foi capaz de contornar os efeitos nefastos do obstáculo externo e inspirou o desenho de uma nova política macroeconômica, que, em linhas gerais, persiste até os dias de hoje. Ao invés da âncora cambial como mecanismo de estabilização dos preços domésticos, que fora inaugurada com o Plano Real, passou-se a adotar o regime de metas inflacionárias, que combinava uma maior flexibilidade da taxa de câmbio, a fixação de um alvo de inflação com patamares fixos de variação para mais ou para menos e uma rígida e obstinada política de geração de superávits fiscais.

Os resultados dessa política logo se fizeram sentir, apesar das profundas 
críticas de economistas heterodoxos de formação desenvolvimentista. Para eles, estaria-se privilegiando metas de estabilização, ao invés de se estimular políticas de crescimento. Apesar do aumento da carga fiscal, a política cambial produziu efeitos positivos sobre a balança comercial e o temor da volta da inflação desvaneceu-se. Reconhecendo a procedência da crítica heterodoxa, o País pagou o preço da estabilização, sacrificando expressivos passos rumo à constituição de um ambiente para o crescimento. Entretanto, esse processo trouxe uma importante lição para os tempos futuros. A construção de uma plataforma consistente para o processo de crescimento econômico não poderia ser construída sem a vigência de um maduro (leia-se estável e duradouro) ambiente de estabilização econômica. E a opção de política econômica adotada consolidou esse processo. Essa foi a lição herdada do duro período de ajustamento estrutural: a estabilização dos preços é um processo lento, penoso, e que, não necessariamente (leia-se automaticamente), conduz ao crescimento econômico, mas, por definição, é uma condição necessária para tal desiderato. A adoção do novo desenho da política econômica foi consolidando um novo ambiente macroeconômico e fiscal, que vem persistindo e que explicitou um novo compromisso com a gestão pública: metas de geração de sistemáticos déficits orçamentários passaram a ser banidas em ambientes de estabilização ${ }^{2}$.

O segundo momento que balançou os alicerces da estabilização construída através do Plano Real ocorreu em dezembro de 2002. A eleição presidencial de Lula criou expectativas de que um suposto "desenvolvimentismo", ainda impreciso conceitualmente, superaria a equivocada dicotomia "estabilização X crescimento", fazendo crer, aos mais inadvertidos, que o novo presidente mudaria drasticamente (e até ingenuamente) os rumos da economia brasileira e, por conseqüência, os próprios fundamentos da estabilização.

No imediato pós-eleição, os índices de preços dispararam, sugerindo que a inflação rapidamente se (re)instauraria. Obviamente que, se tal infortúnio ocorresse e se a suposta mudança de rumo se consumasse, o caminho para a ingovernabilidade estaria aberto e o retorno ao ambiente de descrédito na política econômica (tão comum e reiterado na década de 80 ) voltaria à cena.

Passada a turbulência inicial, oriunda da frustração de expectativas inflacionárias crescentes - e por conta de uma drástica mudança de rumo que não ocorreu -, o País passou a colher frutos de uma inserção externa mais competitiva, de uma recuperação expressiva do mercado interno e de um novo desenho para o crescimento econômico, que contemplava maior dinamismo das exportações e um crescimento doméstico puxado pelo consumo das famílias. Tal quadro foi abalado seriamente quando da eclosão da crise financeira, oriunda da subprime norte-americana, de setembro de 2008, que parece ter sido, atualmente, superada pelo menos em escala nacional.

\footnotetext{
2 Em defesa de Keynes, se é que hoje o referido autor precise dela, saliente-se que tais práticas também explicitaram o equívoco do nexo causal entre políticas de inspiração keynesiana com práticas fiscais gastadoras ou irresponsáveis, herança de uma má formação teórica de economistas obstinadamente anti-keynesianos. Reitere-se, mais uma vez, que um Estado Keynesiano moderno não é incompatível com a perseguição de superávits fiscais. A circunstância e a inserção da política econômica norteará as decisões governamentais, que não podem prescindir do seu legado. Em outros termos: ser keynesiano não implica ser favorável à geração sistemática de déficits públicos e irresponsabilidade fiscal.
} 
O que ficou desse processo? Apesar das mudanças percebidas no âmbito das firmas, que operam no ambiente econômico nacional, e das mudanças institucionais, que caminharam no sentido de conferir uma maior maturidade econômica ao País, essas transformações, não perceptíveis pelo simples exame dos principais agregados macroeconômicos, revelam melhora dos mesmos em relação às duas décadas anteriores. É a esse resultado que chamamos de "reordenamento obediente", uma vez que a conformação produtiva nacional e regional passou a sintonizar-se mais com as mudanças ocorridas no ambiente externo (ditadas pelo paradigma tecnológico da informação), cuja busca por ganhos de competitividade e produtividade nesse âmbito, aliado a um projeto macroeconômico desenhado a partir do Plano Real, gerou um comportamento doméstico de aceitação dessas regras e estratégias de adaptação ao referido padrão tecnológico. A disciplina macroeconômica passou a ser perseguida e obedecida pela política econômica vigente.

Designamos, portanto, de "reordenamento" não apenas a adesão às regras de política macroeconômicas estabelecidas, sem miragens, nem milagres, mas também às sucessivas tentativas de inserção na ordem tecnológica vigente. E de "obediente", na medida em que a busca de aprofundamentos dentro da mesma vai criando, ao longo do tempo, janelas de oportunidade que se entreabrem recursivamente dentro desse (novo) ambiente.

A lição que se extraiu desse processo foi que a aposta na "continuidade" do processo de ajustamento estrutural, produzido pelo Plano Real, revelou não só a maturidade da economia brasileira em conviver com um novo regime de preços, mas de adequar-se a uma nova realidade mundial, onde a busca por competitividade, por novos mercados, por novos processos de trabalho e por novas tecnologias é não somente irreversível, como também deve-se constituir em meta micro e macroeconômica. E tal busca, ao contrário do que possam supor, equivocadamente, alguns estudiosos avessos à compreensão do processo de avanço tecnológico, não pode impedir avanços sociais. Dito de outra forma, a melhoria de indicadores sociais - que, por herança histórica, têm sido dos mais baixos do mundo - deve ser buscada e alcançada tendo por suposto o cenário econômico construído a partir desse novo desenho estrutural, recém montado no País, cuja abertura externa e o Plano Real foram dois importantes desencadeadores e artífices. Os dois novos fundamentos institucionais daí decorrentes - a saber, a moeda e o novo padrão de concorrência entre as empresas - são elementos que vieram para ficar no novo desenho institucional, que vem orientando o País.

Entretanto, apesar de alguns avanços, percebe-se que a capacitação tecnológica interna para as novas janelas de oportunidade abertas pelo novo paradigma tecnológico em formação, ainda são tímidas. Assim, é importante que se estabeleça, internamente, novos vínculos com a capacitação tecnológica e com a montagem de um efetivo sistema nacional de inovação. Tal sistema deverá, por definição, articular firmas, Estado e universidades, para gerar o estabelecimento de uma plataforma para o crescimento econômico e para o desenvolvimento tecnológico. Só assim a enorme dívida social, que continua 
assolando o país, poderá ser equacionada.

Entendemos que a superação da fase de "reordenamento obediente" da última década deverá ser orientada por uma política mais agressiva de P\&D, sintonizada com os avanços tecnológicos do paradigma em gestação. Maiores gastos em pesquisa, em educação e capacitação profissional serão elementos decisivos para a construção de um novo modelo de crescimento auto-sustentado, distributivo e com maior qualificação tecnológica e social. O primeiro passo no sentido da construção de instituições capazes de assegurar essa nova etapa parece que vem sendo dado, na medida em que a economia brasileira vem respondendo positivamente, mas ainda de maneira tímida, aos desafios desse novo ambiente.

O que nos parece claro de toda essa discussão é que o País vem trilhando uma potencialmente fértil trajetória de crescimento, mas que deve alicerçarse com as mudanças em curso no novo paradigma tecno-econômico. A crise financeira internacional de 2008 trouxe, sem dúvida, efeitos perversos sobre o ambiente externo e interno, mas caberá à política econômica vigente impedir retrocessos ao padrão de desenvolvimento econômico a ser construído.

Por enquanto, julga-se precipitado falar-se em um "novo desenvolvimentismo', que mais parece estar na intenção de alguns economistas e correntes de pensamento do que na materialidade da atual trajetória da economia brasileira. Se não vejamos.

\section{A economia brasileira e o "novo desenvolvimentismo"}

O termo "desenvolvimentismo" está ligado à tradição Cepalina, que, a partir da interpretação do processo de substituição de importações, estabeleceu os cânones da construção da industrialização latino-americana, em geral, e brasileira, em particular. Inúmeros estudos se seguiram à clássica obra de Furtado (1971), Formação Econômica do Brasil, escrita em 1955, e da de Conceição Tavares (1972), Auge e Declínio do Processo de substituição de Importações no Brasil, escrito em 1963. Esses estudos serviram como referência a toda uma gama de trabalhos que consagraram definitivamente o termo "desenvolvimentismo" (Fonseca, 2004; Bielschovski, 1988), bem como explicitaram que a década de 80 sepultou seu sentido teórico em explicar os rumos da economia brasileira. Novos aportes eram, então, necessários, capazes de dar conta, de um lado, tanto do esfacelamento da era substitutiva de importações, bem como de tentar incorporar, de outro lado, novos conceitos capazes de dar conta das transformações estruturais em curso. Os anos de 1990 consolidaram avanços no sentido de se compreender melhor os rumos inovadores, que atravessaria a economia brasileira a partir de então.

Nesse sentido, incorporando os elementos supracitados, consideramos não ser inviável falar-se em "novo desenvolvimentismo", conceito proposto por Bresser-Pereira (2004) e explicitado pelos pós-keynesianos brasileiros (Sicsú, Paula e Oreiro, 2005) e por Bresser-Pereira e Gala (2010). Entretanto, consideramos que essa noção deve estar inserida em um ambiente institucional 
capaz de lhe dar sustentação. Trata-se de uma noção que deve ser histórica, enraizada microeconomicamente e sustentada no plano macroeconômico em sintonia com os agentes (plano microeconômico). Sem essa adesão, o conceito cai no vazio ou não eclode socialmente. O que se tem percebido é que a noção de "novo desenvolvimentismo" constitui uma "nova fase" em relação à proposição inicial dos Cepalinos, que trataram da questão do "desenvolvimentismo" de então. Mas isso tudo não é suficiente.

Em nossa visão, o termo "novo desenvolvimentismo" só teria sentido se fosse inserido (embedded) dentro de um ambiente em que operem as forças sociais, políticas, econômicas, institucionais e tecnológicas sintonizadas com o mesmo. Daí a proposição em se avaliar se o conceito de "novo desenvolvimentismo" incorpora analiticamente todas essas dimensões. Ou seja, faz-se necessário incluir novos elementos, tais como os novos padrões de comportamento dos indivíduos:

\begin{abstract}
"Nosso pressuposto é o de que no quadro da globalização a competição entre os Estados-nação aumentou de forma que o desenvolvimento econômico e o catching up dependem da adoção de estratégias nacionais de desenvolvimento baseadas em modelos econômicos com o necessário poder de explicação e de previsão. Enquanto isto não voltar a ocorrer, os países latino-americanos poderão crescer, mas a taxas inferiores às necessárias ao catching up e muito inferiores às dos países asiáticos dinâmicos." (op.cit., p. 665)
\end{abstract}

Esses países, embora tenham adotado "estratégias de desenvolvimento" essencialmente "novo-desenvolvimentistas", não elaboraram, ao contrário do que os autores propõem, uma "nova" teoria econômica, mas foram apenas pragmáticos. Em que consistiriam tais estratégias?

O Novo Desenvolvimentismo estabeleceria um contraponto com o Velho Desenvolvimentismo, na medida em que seria caracterizado por cinco elementos estruturais (ou institucionais). Seriam eles: 1) Industrialização orientada para as exportações, combinada com consumo de massas no mercado interno (em oposição à industrialização orientada pelo estado na substituição de importações); 2) Criação, pelo Estado, das oportunidades de investimento e redução das desigualdades econômicas (em oposição a seu papel central na obtenção de poupança e realização de investimento); 3) Política industrial subsidiária, mas estratégica (em oposição a seu papel como central); 4) Rejeição aos dois déficits (em oposição a certa ambiguidade em relação aos déficits públicos e em conta corrente): em caso de doença holandesa deverá apresentar superávit fiscal e na conta corrente; e 5) Nenhuma complacência em relação à inflação (em oposição à relativa complacência com a mesma no PSI).

Deve-se salientar a importância de dois pontos a respeito do desenho do novo desenvolvimentismo. Em primeiro lugar, a tarefa do Estado é substituída: invés de ocupar-se da "acumulação primitiva de capital e promover a revolução industrial”, sua função é diminuída e a do mercado aumentada; há maior 
parceria com o setor privado, que passaria a ocupar-se com grande parte dos investimentos; e ao Estado caberia investir em certos setores estratégicos. E, em segundo lugar, é crucial a diferença do novo-desenvolvimentismo com a ortodoxia (convencional), no que tange a estratégias de desenvolvimento em relação às estratégias de estabilidade macroeconômica. Para os últimos, há uma proposição de reformas e de políticas baseadas no fundamentalismo de mercado, herdadas do favorecimento "globalizado" às nações ricas. Tais fundamentos (neoclássicos) ignorariam o próprio conceito de Nação, estabelecendo internamente instituições estritamente ocupadas com "direitos de propriedade e dos contratos" (op. cit., p. 681) ${ }^{3}$. O novo desenvolvimentismo, ao contrário da ortodoxia convencional, que é, segundo os autores, "fundamentalista de mercado", acredita na coordenação pelo mercado, que, aliás, é também uma instituição. Esses pontos sugerem a relevância do aprofundamento teórico do referido conceito, articulando a macroeconomia proposta com aspectos microeconômicos derivados do comportamento dos agentes, das firmas e das tecnologias.

\section{Considerações finais}

Apesar da importância do conceito de "novo desenvolvimentismo", julgamos que os autores incorporam escassos elementos institucionais na análise. A mediação entre comportamento dos agentes, a partir do desenho institucional definido no plano econômico, não permite que se perceba como os indivíduos guiariam suas decisões, ações, padrões de comportamento e hábitos, a partir do horizonte desenvolvimentista desenhado do ponto de vista macroeconômico. Concordamos que estratégias podem vir a se institucionalizar, mas para tanto a adesão dos indivíduos, no plano microeconômico, é crucial. E isto a análise de Bresser-Pereira e Gala (2010) não contempla.

Sob essa égide, países sem regras estariam condenados ao retrocesso e estagnação econômica. Julga-se que, junto com o regramento, mas não só através dele, todo o aparato cultural, histórico, comportamental e os hábitos da população é que condiciona e orienta as mudanças institucionais, que, isto sim, guiam o processo de desenvolvimento econômico. E consideramos que tal perspectiva analítica deve ser incorporada.

\footnotetext{
3 Não discordamos desse argumento, mas o consideramos reducionista. Há forte influencia da NEI, segundo a qual a minimização dos custos de transação e a garantia dos direitos de propriedade assegurariam eficiência e crescimento estável. Nessas proposições há um caráter fortemente neoclássico, sugerindo que o "ambiente institucional" corrigiria distorções e conduziria a economia à prosperidade. Nem Douglass North, nem Williamson concordariam com essa assertiva, embora a "ordem sistêmica”, para esses autores, tenha um papel proeminente, ao contrário da proposição do Antigo Institucionalismo, que nos parece mais adequada ao esquema macroeconômico sugerido pelos autores.
} 


\section{Referências}

Belluzzo, L. G.; Almeida, J. G. (2002). Depois da Queda: A economia brasileira da crise da divida aos impasses do Real. Rio de Janeiro, Civilização Brasileira, 359 p.

Bresser-Pereira, L. C.; Gala, P. (2010). Macroeconomia estruturalista do desenvolvimento. Revista de Economia Política, vol. 30, nº 4 (120), pp. 663-686, outubro-dezembro/2010.

Bresser-Pereira, L.C. (2004). Novo-desenvolvimentismo. Folha de São Paulo. Caderno Dinheiro.

Bielchowsky, R., (1988). Pensamento Econômico Brasileiro: o ciclo ideológico do desenvolvimentismo. Rio de Janeiro: IPEA.

Castro, A. B.; Possas, M.; Proença, A. (1996). Estratégias Empresariais na Indústria Brasileira: discutindo mudanças. Rio de Janeiro, Forense Universitária, 288 p.

Castro, A. B. (1997). Renegade Development: Rise and Demise of StateLed Development in Brazil. In: Semináio Internacional Instituições e Desenvolvimento Econômico, Rio de Janeiro.

Coase, R. H. (1991) Nobel Lecture: The Institutional Structure of Production. In: Williamson, O. E.; Winter, S. G. (1993). The Nature of the Firm: origins, evolution, and development. New York/Oxford, Oxford University Press, (Original 1937).

Conceição, O. A. C. (2009). Instituições e Crescimento econômico: da "tecnologia social" de Nelson à "causalidade vebleniana" de Hodgson. In: XXXVII Encontro Nacional de Economia da Anpec Foz do Iguaçu.

Coutinho, L.; Ferraz, J. C. (1994) (Coord.). Estudo da Competitividade da Indústria Brasileira. 2 ed. Campinas: Edit. Unicamp, 510 p.

Dosi, G. (1988a). The nature of the innovative process. In: Dosi, G. et alii (eds.). Technical change and Economic Theory. London: Pinter Publishers.

Dosi, G. (1988b). Sources, Procedures, and Microeconomic Effects of Innovation. Journal of Economic Literature, v. 26, p. 1120-1171.

Fonseca, P. C. D. (2003a). Sobre a intencionalidade da política industrializante no Brasil na década de 1930. Revista de economia política, n. 89, p.133-148, São Paulo.

Fonseca, P. C. D. (2003b). O processo de substituição de importações. In: REGO, José Márcio e MARQUES, Rosa Maria. Formação econômica do Brasil. São Paulo, Saraiva, 2003. Cap. 11, p. 248-282.

Fonseca, P. C. D. (2004). Gênese e precursores do desenvolvimentismo no Brasil. Pesquisa \& debate. São Paulo, PUCSP, v. 15, n. 2(26), jul./dez. p.225-56.

Fonseca, P. C. D. (2009). "A política e seu lugar no estruturalismo: Celso Furtado e o impacto da Grande Depressão no Brasil”. XXXVII Encontro Nacional da ANPEC. Foz do Iguaçu.

Fonseca, P. C. D. e Monteiro, Sérgio M. Credibilidade e populismo: a política 
econômica dos governos Vargas e Goulart. (2005).Revista brasileira de economia. Rio de Janeiro, n. 2, v. 59, abr/jun 2005, p. 215-243. Ou: Anais do XXX Encontro Nacional de Economia da ANPEC/SEP. Nova Friburgo, 2002 [CD, www. anpec,org.br].

Furtado, C. (1971). Formação econômica do Brasil. São Paulo, Nacional.

Freeman, C.; Louçã, F. (2001). As time Goes By: From the Industrial Revolutions to the Information Revolution. New York: Oxford University Press, $407 \mathrm{p}$.

Freeman, C.; Perez, C. Structural crises of adjustment business, cycles and investment behaviour. (1988). In: DOSI, G. et alii (eds.) Technical Change and Economic Theory. London: Pinter Publishers.

Hodgson, G. M. (1988). Economics and Institutions: A Manifesto for a Modern Institutional Economics. Cambridge and Philadelphia: Polity Press and University of Pennsylvania Press, 1988.

Hodgson, G. M. (1993). Economics and Evolution: Bringing Life Back Into Economics. Cambridge UK and Ann Arbor MI: Polity Press and University of Michigan Press.

Hodgson, G. M. (2000). What Is the Essence of Institutional Economics? Journal of Economic Issues. New York: Association for Evolutionary Economics, 34.2: 317 329.

Hodgson, G. M. (2002). The Evolution of Institutions: An Agenda for Future Theoretical Research. Constitutional Political Economy. ABI/INFORM Global, 13, 2; p. 111-127.

Hodgson, G. M. (2004). Veblen and Darwinism. International Review of Sociology/ Revue Internationale de Sociologie. Cambridge, UK: Cambridge University, Vol. 14, No. 3.

Hodgson, G. M. (2006a). Economics in the Shadows of Darwin and Marx: Essays on Institutional and Evolutionary Themes. Cheltenham: Edward Elgar, 2006.

Hodgson, G. M. (2006b). What Are Institutions? Journal of Economic Issues. 40.1: $1-25$.

Hodgson, G. M. (2007). The Revival of Veblenian Institutional Economics. Journal of Economic Issues. 41.2: 325-340.

Hodgons and T. Knudsen. (2006). Why we need a generalized Darwinism, and why generalized Darwinism is not enough. Journal of Economic Behavior \& Organization. 61: 1-19.

Matthews, R. C. O. (1986). The Economics of Institutions and the Sources of Growth. The Economic Journal, v. 96, p. 903-918.

Nelson, R. R.; Winter, S. G. (1982). An Evolutionary Theory of Economic Change. Cambridge, MA: Harvard University Press, 1982.

Nelson, R. R.; Winter, S. G. (2002). Evolutionary Theorizing in Economics. Journal of Economic Perspectives. V. 16, n. 2, p. 23-46.

Nelson, R. R. (1995). Recent Evolutionary Theorizing About Economic Change. Journal of Economic Literature. 33.1: 48-90.

Nelson, R. R. (1998). The agenda for growth theory: a different point of view. 
Cambridge Journal of Economics. v. 22, p. 497-520. 1998.

Nelson, R. R. \& Sampat, B. (2001). Las instituciones como factor que regula el desempeño económico. Revista de Economia Institucional. $\mathrm{N}^{\circ}$ 5, Segundo Semestre.

Nelson, R. R. \& Sampat, B. (2002). Bringing institutions into evolutionary growth theory. Journal of Evolutionary Economics. Verlag, Spring, v. 12, p. 17-28.

Nelson, R. R. \& Sampat, B. (2006). Economic Development From the Perspective of Evolutionary Economic Theory. Working Papers in Technology Governance and Economic Dynamics no. 2. TECHNOLOGY GOVERNANCE. New York: Columbia University, January.

Nelson, R. R. \& Sampat, B. (2008). What enables rapid economic progress: What are the needed institutions? Research Policy, 37, p. 1-11.

North, D. C. (1990). Institutions, Institutional Change and Economic Performance. New York: Cambridge University Press.

North, D. C. (1991). Institutions. Journal of Economic Perspectives. 5.1: 97-112.

North, D. C. (1994).Economic Performance Through Time. American Economic Review. 84.3: 359-367.

North, D. C. (2005). Understanding the Process of Economic Change. Princeton and Oxford: Princeton University Press.

Perez, C. (2007). GREAT SURGES OF DEVELOPMENT AND ALTERNATIVE FORMS OF GLOBALIZATION. Universities of Cambridge and Sussex, U.K. and Technological University of Tallinn, Estonia, January 2007. To be published in Portuguese in: Theotonio Dos Santos and Carlos Eduardo Martins, eds. (2007) Long Duration and Conjuncture in Contemporary Capitalism REGGENUNESCO/UNU, Universidad Federal de Santa Catarina.

Perez, C. (2002).Technological Revolutions and Financial Capital: The Dynamics of Bubbles and Golden Ages. Cheltenham: Elgar.

Perez, C. (2004). Finance and technical change: A long-term view. CERF, Judge Institute, Cambridge University, and SPRU, University of Sussex, UK. To appear in H. Hanusch and A. Pyka, eds., The Elgar Companion to NeoSchumpeterian Economics, Edward Elgar, Cheltenham.

Samuels, W. J. (1195). The present state of institutional economics. Cambridge Journal of Economics. v. 19, p. 569-590.

Sicsú, J., Paula, L.F. e Michel, R., org. (2005). Novo-Desenvolvimentismo: um projeto nacional de crescimento com eqüidade social. Barueri/Rio de Janeiro: Manole/ Fundação Konrad Adenauer.

Tavares, M. da C. (1972). Da substituição de importações ao capitalismo financeiro. Rio de Janeiro, Zahar.

Tavares, M. da C. Destruição Não Criadora. (1999). São Paulo: Editora Record.

Zysman, J. (1994). How Institutions Create Historically Rooted Trajectories of Growth. Industrial and Corporate Change. v. 3, n. 1, p. 243-283. 